\title{
Children First Study II: an educational programme on cardiovascular prevention in public schools can reduce parents' cardiovascular risk
}

\author{
(iD) Cristiano J. M. Pinto ${ }^{1}$ \\ (iD) Luciana S. Fornari ${ }^{1}$ \\ (iD) Silvia M. R. Oyama² \\ (iD) Maria M. D. Rodrigues ${ }^{2}$ \\ (iD) Taciana Davanço² \\ (iD) Bruno Caramelli ${ }^{3}$
}

1. Universidade de São Paulo, São Paulo, SP, Brasil. 2. Universidade Padre Anchieta, São Paulo, SP, Brasil. 3. InCor, Universidade de São Paulo, São Paulo, SP, Brasil.

http://dx.doi.org/10.1590/1806-9282.66.9.1217

\section{SUMMARY}

OBJECTIVE: The aim of this study was to analyze whether the implementation of a multidisciplinary educational programme for cardiovascular prevention in public schools can contribute to reducing the Fram

INGHAM CARDIOVASCULAR RISK SCORE OF THE CHILDREN'S PARENTS AFTER ONE YEAR.

METHODS: This was a prospective, community-based, case-control study carried out in public schools in Sao Paulo, Brasil. Students were randomized to receive healthy lifestyle recommendations by two different approaches. The control group received written cardiovascular health educational brochures for their parents. The intervention group received the same brochures for the parents, and the children were exposed to a weekly educational programme on cardiovascular prevention with a multidisciplinary health team for one year. Clinical and laboratorial data were collected at the onset and end of the study.

RESULTS: We studied 265 children and their 418 parents. At the baseline, the rate of parents with intermediate or high Framingham scores (risk of cardiovascular disease over the next 10 years greater than 10\%) was $6.9 \%$ in the control group and $13.3 \%$ in the intervention group. After one year, the rate of parents with intermediate or high Framingham risk score was reduced by $22.2 \%$ in the intervention group and increased by $33.3 \%$ in the control group ( $p=0.031)$. The cardiovascular risk factors that improved in the intervention group were blood pressure, LDL-cholesterol (low-density lipoprotein cholesterol), and glucose levels.

CONCLUSION: An educational programme on cardiovascular prevention for school-age children in public schools can reduce the cardiovascular risk of their parents.

KEYWORDS: Cardiovascular diseases/prevention \& control. Child. Parents. Education. Schools.

\section{BACKGROUND}

Worldwide, the prevalence of cardiovascular disease has decreased in high-income countries, while there has been a significant increase in middle- and low-income countries ${ }^{1}$. Morbidity and mortality related to cardiovascular diseases have important socioeconomic impacts, suggesting the need to intensify preventive measures, 
which have a greater impact than curative measures, especially in low-income countries ${ }^{1-4}$.

The prevention of cardiovascular diseases, whose key aspect is the control of atherosclerosis, depends on the adoption of healthy habits and the control of preventable cardiovascular risk factors such as sedentarism, obesity, dyslipidemia, hypertension, diabetes, and smoking. Governmental organizations promote health with an emphasis on education in schools ${ }^{2}$, and this strategy has been supported by several recent studies that demonstrated a correlation between the cardiovascular risk factors of the children and their parents, such as the PEP Family Heart Study ${ }^{5}$.

In a previous study, we demonstrated that health promotion policies in private schools can surpass what is assimilated by the children and reach their parents, changing the whole family culture and influencing parents' lifestyle habits and, ultimately, their cardiovascular risk ${ }^{6}$. Similar studies in England ${ }^{7}$ and Germany ${ }^{5}$ have also shown positive results. However, there is a shortage of studies that evaluate cardiovascular prevention with educational programmes in public schools with low-income families. In addition, low-income and developing countries such as Brasil are facing now a profound health challenge with the current scenario of cardiovascular morbidity and mortality that demands urgent preventive measures ${ }^{3,8}$.

Therefore, the objective of this study was to evaluate whether the implementation of a multidisciplinary programme on cardiovascular health in public schools, aimed at presenting concepts of primary prevention of cardiovascular heart disease (CHD) to children, can contribute to a reduction in the cardiovascular risk of their parents.

\section{METHODS}

\section{Study design}

This was a one-year prospective, community-based, case-control study, conducted in two randomly chosen public schools in the city of Campo Limpo Paulista, Sao Paulo, in Brasil (the schools were selected from areas with the same average socioeconomic status as the city as a whole). These were urban schools with low-income students, and they were comparable in their characteristics. The students from these two schools and their parents received two different health interventions during the academic year, as in the methods of the Children First I Study conducted by Fornari et al. ${ }^{6}$.

At one of the schools (the control group), we delivered written healthy-lifestyle educational brochures (nutrition, exercise, and smoking cessation) to the parents in April, June, and September 2012. At the other school (the intervention group), the same educational brochures were delivered to the parents and, in addition, the children were exposed to a weekly educational programme for cardiovascular disease prevention presented by a multidisciplinary health team throughout the 2012 school year.

The ethical committee of the Faculty of Medicine of the Sao Paulo University and the local school authorities approved this study. All parents and children signed informed consent.

\section{Study population}

We studied 418 parents of students aged 6 to 10 years old. The control group had 216 parents (mean age 37.9 years, $68.1 \%$ female), and the intervention group had 202 parents (mean age 39.5 years, 63.9\% female).

The students evaluated were all the students from the first to the fifth grade of the elementary schools of the two schools studied, who attended school both in the morning and afternoon.

\section{Sample size}

The size of the sample was based on information from the Children First I Study ${ }^{6}$, which was a pilot study with 30 parents from the same school that found that the proportion of parents with moderate/ high Framingham cardiovascular risk was 10\%. To aim for a $70 \%$ reduction in the number of parents in the moderate/high Framingham cardiovascular risk category $(p=0.05)$, we needed 150 parents in each group (control and intervention).

\section{Exclusion criteria}

To avoid the influence of potential confounders, we applied some exclusion criteria. We excluded children and/or parents who did not agree to participate in the study; those who were taking immunosuppressive drugs; parents with a known atherosclerotic disease such as angina or myocardial infarction, stroke and/or peripheral arterial disease; and parents with untreated hypothyroidism, hypopituitarism, nephrotic syndrome, chronic renal failure, storage diseases, lupus or acquired immunodeficiency syndrome.

\section{Data collection}

Data were collected at the beginning of the study (February 2012) and at the end of the academic year 
(December 2012), on two consecutive weekends inside the school buildings, from the parents of the children at both schools. The survey included their personal and family history, weight, height, arterial blood pressure, and laboratory tests (glucose, total cholesterol, LDL-cholesterol, HDL-cholesterol, and triglycerides.

\section{Multidisciplinary health team}

A trained multidisciplinary health team that included nurses, physical education teachers, nutritionists, physiotherapists, and psychologists collected all the data from the children and their parents. This same multidisciplinary health team worked during the year with the children in the intervention group, presenting different activities directed at cardiovascular disease prevention that were supervised by the study researchers.

\section{Measurements}

A trained multidisciplinary health team manually performed all measurements in the parents according to the study guidelines. Weight and height were measured in triplicate, without shoes, and while wearing light clothing, using a digital scale accurate to $100 \mathrm{~g}$ and a portable stadiometer accurate to $1 \mathrm{~mm}$. The body mass index (BMI) was calculated as the weight in kilograms divided by the height squared in meters squared. Systolic and diastolic blood pressure were measured according to the technique recommended by national guideline ${ }^{s 9}$. The subjects were seated and had rested for 5 minutes before the blood pressure measurement, which was taken twice on each arm using an appropriate cuff size; the two similar measurements were averaged for analysis. Blood was collected by traditional venepuncture, and fasting cholesterol, LDL-cholesterol, HDL-cholesterol, triglycerides, and glucose were determined by enzymatic methods. The stratification by socioeconomic status was obtained by national measurement parameters ${ }^{10}$.

\section{Risk factor definitions for parents}

To measure and compare the cardiovascular risk of the parents, we used the Framingham score. The score estimates the risk of the individual having cardiovascular disease in the next 10 years and includes 3 levels: low risk ( $<10 \%$ risk of $\mathrm{CHD})$, intermediate risk ( $>10 \%$ risk of CHD), and high risk $(>20 \%$ risk of $\mathrm{CHD})^{2}$. We used the calculator available on the Framingham Project website, which uses the lipid profile as the basis for the calculation, to calculate the risk for the parents ${ }^{11}$.

For the isolated risk factors, obesity was defined as a $\mathrm{BMI} \geq 30 \mathrm{~kg} / \mathrm{m}^{2}$ according to the national guideline ${ }^{9}$; hypertension was defined as a systolic blood pressure $\geq 140 \mathrm{mmHg}$ and/or diastolic blood pressure $\geq 90 \mathrm{mmHg}^{9}$; and abnormal lipid levels were defined as total cholesterol $>200 \mathrm{mg} / \mathrm{dl}$, triglycerides $>150 \mathrm{mg} / \mathrm{dl}$, HDL-cholesterol $<40 \mathrm{mg} / \mathrm{dl}$ for men and $<50 \mathrm{mg} / \mathrm{dl}$ for women, and LDL-cholesterol $>130 \mathrm{mg} / \mathrm{dl}^{12}$.

Multidisciplinary educational programme for cardiovascular prevention

In the intervention group, the children attended a cardiovascular health education programme that followed the same protocol used in the study by Fornari et al. ${ }^{6}$, with hour-long weekly activities at the children's school. The intervention was carried out by the professionals of the multidisciplinary health team and was supervised by the study researchers. This intervention tried to teach children, in age-appropriate ways, the concepts of healthy nutrition, the importance of a more active lifestyle with more physical exercise, and the hazardous effects of smoking, all using videos, theatre with puppets or actors, sports, play, and educational games on cardiovascular health topics. Psychologists and teachers supervised this work, and children were not asked to feel responsible for their families' lifestyle modifications in either group.

\section{Ethics approval and consent to participate}

The study was approved by the ethical committee of the Clinical Hospital of the Faculty of Medicine of the Sao Paulo University (protocol no. 1147/09) and the local school authorities approved this study. All parents and children signed informed consent.

\section{Statistical analysis}

The categorical clinical variables were described as absolute and relative frequencies (percentages). The chi-squared test or Fisher's exact test (when at least one of the expected frequencies was less than 5) were used to verify the association between the categorical clinical variables in the study groups at the baseline. The continuous clinical variables were expressed as means and standard deviation, and the Student's t-test was used for comparisons between the two groups at the baseline. The analysis of the change in the number of parents in the high-risk categories of 
the Framingham was performed with the McNemar test. All statistical analyses were performed by SPSS 17.0 for Windows, according to a predefined analysis plan. All tests were 2- tailed, and p-values of less than 0.05 were considered statistically significant.

\section{RESULTS}

We studied 418 parents and 265 children, with 216 parents in the control group (137 children) and 202 in the intervention group (128 children). In the control group, the mean age was 37.9 years, and $68.1 \%$ were female, while in the intervention group, the mean age was 39.5 years, and $63.9 \%$ were female.

At baseline, there were no differences between the two groups of parents (control and intervention) in terms of their clinical characteristics, with the exception of a higher prevalence of hypertension in the intervention group (29.7\%) compared to the control group $(19.4 \%, p=0.015)$ and abnormal cholesterol in the intervention group (41.1\%) compared to the control group $(28.7 \%, \mathrm{p}=0.08)$. Table 1 shows that the continuous clinical characteristics were similar in the two groups, with the exception of higher levels of systolic blood pressure (122.4 in the intervention group vs. 118.8 in the control group, $p=0.004$ ), diastolic blood pressure (84.6 in the intervention group vs. 76.2 in the control group, $p<0.001$ ), total cholesterol (192.7 in the intervention group vs. 184.2 in the control group, $\mathrm{p}=0.009$ ), and LDL-cholesterol (115.0 in the intervention group vs. 108.3 in the control group, 0.017) in the

TABLE 1. CHARACTERISTICS OF PARENTS IN THE CONTROL AND INTERVENTION GROUPS AT THE BEGINNING OF THE STUDY (CONTINUOUS VARIABLES). VALUES ARE EXPRESSED AS THE MEANS (SD).

\begin{tabular}{l|l|l|l} 
& \multicolumn{3}{|l}{ Groups } \\
\hline Variables & Control & Intervention & $\mathrm{p}^{\mathrm{a}}$ \\
\hline Age (years) & $37.9(8.6)$ & $39.5(8.8)$ & 0.070 \\
\hline BMI (kg/m2) & $27.4(5.5)$ & $27.6(5.1)$ & 0.692 \\
\hline $\begin{array}{l}\text { Systolic blood pressure } \\
\text { (mmHg) }\end{array}$ & $118.8(15.4)$ & $122.4(13.8)$ & 0.004 \\
\hline $\begin{array}{l}\text { Diastolic blood pressure } \\
\text { (mmHg) }\end{array}$ & $76.2(10.2)$ & $84.6(10.4)$ & $<0.001$ \\
\hline Smoking & $20(9.3)$ & $21(10.4)$ & 0.695 \\
\hline Total cholesterol (mg/dl) & $184.2(38.4)$ & $192.7(37.2)$ & 0.009 \\
\hline Triglycerides $(\mathrm{mg} / \mathrm{dl})$ & $120.0(98.9)$ & $128.2(89.9)$ & 0.109 \\
\hline HDL-cholesterol (mg/dl) & $52.0(18.6)$ & $52.6(15.2)$ & 0.145 \\
\hline LDL-cholesterol (mg/dl) & $108.3(35.6)$ & $115.0(30.9)$ & 0.017 \\
\hline Glucose (mg/dl) & $85.6(25.2)$ & $85.8(26.6)$ & 0.847 \\
\hline
\end{tabular}

a Statistical significance according to Wilcoxon test for comparisons of continuous variables between two independent groups at the baseline. intervention group, pointing to a slightly higher risk profile in this group.

We found that, at the beginning of the study, $6.9 \%$ of the parents in the control group and $13.3 \%$ of the intervention group had intermediate/high Framingham risk scores, meaning that they had a $>10 \%$ risk of developing CHD in the next 10 years. After the intervention with the children in the schools, we observed that the intervention group showed a reduction in the number of parents in this high-risk category of the Framingham (27 to 21 parents with $>10 \%$ risk of developing CHD, $p=0.031$ ) compared to an increase in the control group (15 to 20 parents with $>10 \%$ risk of developing CHD) (Figure 1).

In this sample, these findings correspond to a $22.2 \%$ reduction in the intervention group compared to a $33.3 \%$ increase in the control group. In other words, $22.2 \%$ of the parents in the intervention group were able to change to a low-risk category after the educational intervention with their children in schools.

Table 2 shows the continuous clinical characteristics of parents from the two groups before and after the educational intervention with children for a year. We observed that, in the intervention group, there was a reduction in systolic blood pressure (122.4 to $118.4 \mathrm{mmHg}, \mathrm{p}<0.001$ ), diastolic blood pressure ( 84.6 to $80.1 \mathrm{mmHg}, \mathrm{p}<0.001$ ), and glucose ( 85.8 to $80.3 \mathrm{mg} /$ $\mathrm{dl}, \mathrm{p}<0.001$ ), and both groups demonstrated a reduction in HDL-cholesterol (52 to $46.9 \mathrm{mg} / \mathrm{dl}, \mathrm{p}<0.001$ in the control group and 52.6 to $46.4 \mathrm{mg} / \mathrm{dl}, \mathrm{p}<0.001 \mathrm{in}$ the intervention group). The control group also demonstrated an increase in the average Framingham risk score (3.7 to 4.1, $\mathrm{p}=0.001$ ). (table 2 )

\section{DISCUSSION}

Several studies have evaluated cardiovascular risk factor profiles among children and parents in the school environment ${ }^{5,6,13,14}$. However, few have evaluated the impact that a multidisciplinary intervention could have on the profile of parents' habits and cardiovascular risk factors, especially in populations with lower socioeconomic levels.

Golan et al. ${ }^{13}$ conducted a small study (60 obese children) that evaluated the impact of two behavioral approaches (parents only vs. children only) for the treatment of childhood obesity on the parents' weight, eating habits, and activity habits, as well as their cardiovascular risk factors. He found that the 
parents-only intervention was more effective at reducing the parents' weight than the children-only intervention. In our study, however, we conducted a more structured multidisciplinary educational approach with the schoolchildren, which included nutritionists, physical education teachers, nurses, physiotherapists, and school teachers who planned interventions tailored to the children's specific ages. We did not analyze only the parents' weight but rather included multiple cardiovascular risk factors that contribute to the Framingham cardiovascular risk score and prioritized the educational intervention with children as a way of evaluating children as the main tool for changing their parents' habits.

A study in Colombia with 1216 children and 928 parents showed that an educational intervention with children in schools led to an improvement in the knowledge, attitudes, and habits related to a healthy diet and a more active lifestyle in both parents and children ${ }^{15}$. Our study performed a more objective evaluation and detected the reduction of the parents 'cardiovascular risk after an educational intervention directed at the children.

This study is a follow-up to the Children First I

TABLE 2. CHARACTERISTICS OF PARENTS IN THE CONTROL AND INTERVENTION GROUPS BEFORE AND AFTER THE CHILDREN'S EDUCATIONAL INTERVENTION (CONTINUOUS VARIABLES). VALUES ARE EXPRESSED ASTHE MEANS (SD).

\begin{tabular}{|c|c|c|c|c|c|c|}
\hline & \multicolumn{6}{|l|}{ Groups } \\
\hline & \multicolumn{3}{|l|}{ Control } & \multicolumn{3}{|l|}{ Intervention } \\
\hline & Before & After & pa & Before & After & $\mathrm{pa}$ \\
\hline $\mathrm{BMI}(\mathrm{kg} / \mathrm{m} 2)$ & $27.4(5.5)$ & $27.5(5.4)$ & 0.012 & $27.6(5.1)$ & $27.7(5.2)$ & 0.052 \\
\hline Systolic blood pressure $(\mathrm{mmHg})$ & $118.8(15.4)$ & $118.4(16.7)$ & 0.552 & $122.4(13.8)$ & $118.4(12.9)$ & $<0.001$ \\
\hline Diastolic blood pressure $(\mathrm{mmHg})$ & $76.2(10.2)$ & $77.5(10.1)$ & 0.091 & $84.6(10.4)$ & $80.1(8.9)$ & $<0.001$ \\
\hline Total cholesterol (mg/dl) & $184.2(38.4)$ & $181.5(40.8)$ & 0.058 & $192.7(37.2)$ & $189.6(37.8)$ & 0.348 \\
\hline Triglycerides (md/dl) & $120.0(98.9)$ & $137.4(159.3)$ & 0.003 & $128.2(89.9)$ & $137.6(117.0)$ & 0.071 \\
\hline HDL-cholesterol (mg/dl) & $52.0(18.6)$ & $46.9(11.4)$ & $<0.001$ & $52.6(15.2)$ & $46.4(12.5)$ & $<0.001$ \\
\hline LDL-cholesterol (mg/dl) & $108.3(35.6)$ & $114.7(50.6)$ & 0.766 & $115.0(30.9)$ & $122.1(50.4)$ & 0.008 \\
\hline Glucose (mg/dl) & $85.6(25.2)$ & $83.8(30.6)$ & 0.003 & $85.8(26.6)$ & $80.3(21.8)$ & $<0.001$ \\
\hline Average Framingham risk (\%) & $3.7(4.9)$ & $4.1(5.7)$ & 0.001 & $5.0(6.3)$ & $4.9(6.2)$ & 0.227 \\
\hline
\end{tabular}

HDL-cholesterol, high-density lipoprotein cholesterol; LDL-cholesterol, low-density lipoprotein cholesterol. a Statistical significance according to Wilcoxon test for related samples.

FIGURE 1. PARENTS FROM THE INTERVENTION AND CONTROL GROUPS IN THE HIGH/INTERMEDIATE-RISK CATEGORIES OF THE FRAMINGHAM. PINTO CJM, 2020.

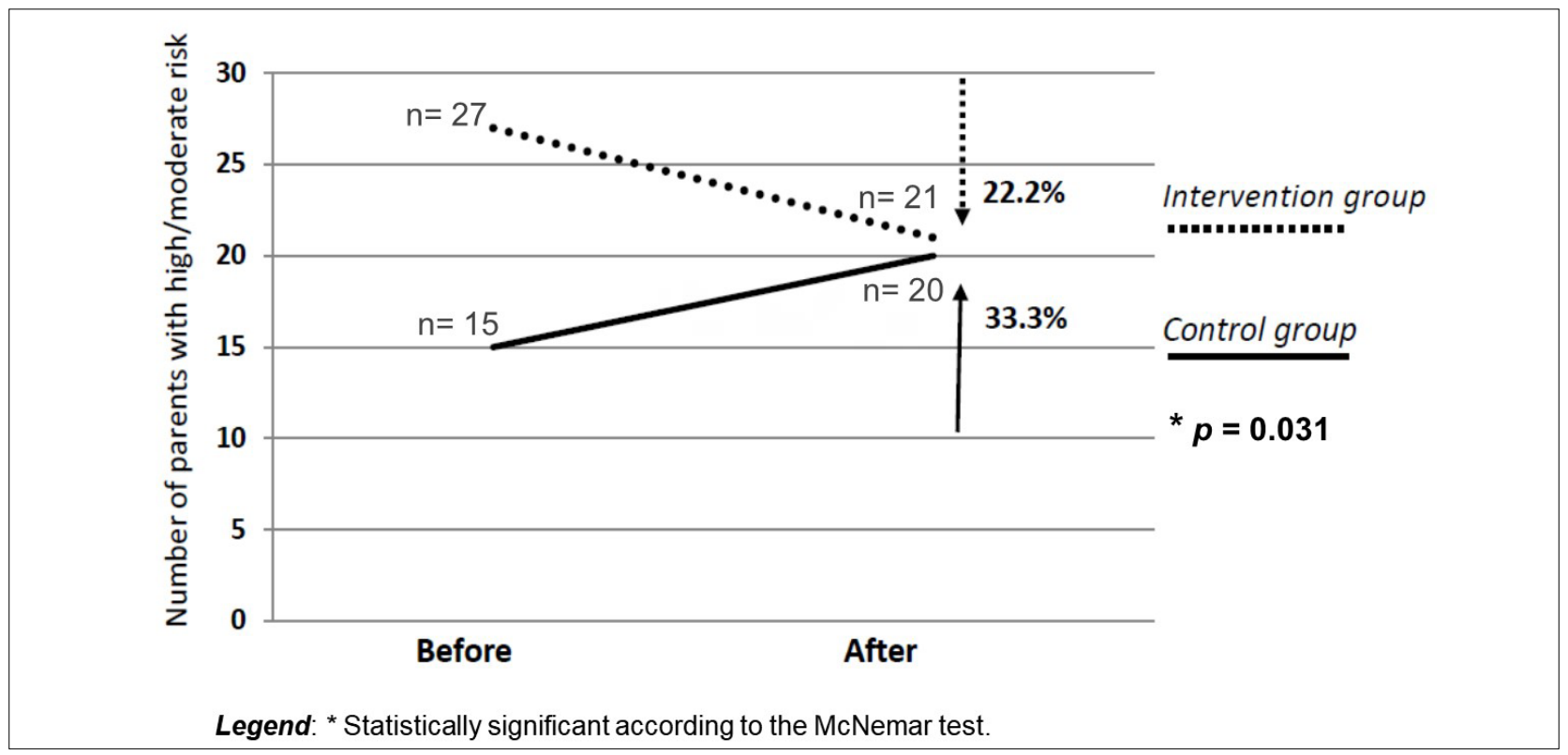


Study ${ }^{6}$ that evaluated the reduction of parents' cardiovascular risk after an educational intervention with children in private schools with a higher average of socioeconomic level. After that study, we speculated whether the findings could be applied to public schools with lower-income families.

In the Children First I Study ${ }^{6}$ there was a considerably greater reduction in the number of parents in the intermediate/high Framingham risk category at the end of the study (91\%) when compared to the Children First II study (22.2\%), although both reductions were statistically significant. However, some considerations need to be made regarding this different behavior in the two studies.

At the beginning of the Children First II Study, the intervention group demonstrated a slightly higher cardiovascular risk profile (Table 1), with higher systolic blood pressure levels (122.4 in the intervention group and 118.8 in the control group, $\mathrm{p}=0.004$ ), higher levels of diastolic blood pressure (84.6 in the intervention group and 76.2 in the control group, $\mathrm{p}<0.001$ ), higher total cholesterol levels (192.7 in the intervention group and 184.2 in the control group, $\mathrm{p}=0.009$ ), and higher levels of LDL cholesterol (115 in the intervention group and 108 in the control group, $\mathrm{p}=0.017$ ).

In addition to a slightly higher cardiovascular risk in the intervention group, another factor that increased the impact of reducing cardiovascular risk in this group was the fact that there was an increase in the cardiovascular risk of the control group by the end of the study. The average Framingham risk score increased in the control group (3.7 to 4.1 at the end of the study, $\mathrm{p}=0.001$ ), (Table 2 ), and there was a $33.3 \%$ increase in the number of control group parents in the intermediate/high score category of the Framingham; at the same time, there was a $22.2 \%$ decrease in the number of parents in those categories in the intervention group ( $\mathrm{p}=0.031)$ (Figure 1).

Some hypotheses may be put forward to explain the different results found in the Children First I and II studies. Perhaps high-income population groups have greater access to healthier foods such as fruits, vegetables, and low-fat alternatives. Indeed, a Brazilian study analyzed the treatment for dyslipidemia among patients with diabetes and observed that people with higher socioeconomic levels have better follow-up by private or insurance doctors, possibly explaining better health outcomes ${ }^{16}$.

Another important factor that the researchers noticed was that public school teachers had less involvement in the didactic activities administered by the multidisciplinary team and, consequently, may have had a smaller contribution concerning the reinforcement of the concepts of cardiovascular health with the children. This hypothesis can be corroborated in a publication of similar studies from England ${ }^{7}$ and Spain ${ }^{17}$, that highlights that the involvement of children's teachers is essential to the success of the intervention.

In summary, the Children First II study showed that there was a reduction in the parents' cardiovascular risk influenced by the educational multidisciplinary intervention on cardiovascular health attended by their children in public schools.

Our study has some limitations. The sample size, despite being larger than that of the Children First I study $^{6}$ is still slightly small. The apparently smaller role of teachers in the multidisciplinary intervention in public schools cannot be adequately measured. Perhaps a study where the intervention was mediated primarily by the teacher in contact with the children and had the support of a multidisciplinary team at distance carried out in a multicentric format both in public and private schools, could clarify this question better.

In addition, our study, like the Children First I study $^{6}$, evaluated the results of one academic year, and we cannot confirm that these results would persist for a longer period. Other studies designed for longer periods of time and with greater sample sizes would be necessary to address these issues.

Another factor is that, at the baseline, the control and intervention groups had some differences in systolic and diastolic blood pressures and lipid profiles. This was a condition found by chance that could not be changed.

However, this study confirms the findings of the Children First $\mathrm{I}^{6}$ study and provides more evidence that multidisciplinary health education interventions with children in schools can decrease their cardiovascular risk.

\section{CONCLUSIONS}

In conclusion, this study provided evidence that an educational program for cardiovascular prevention directed to school-aged children in public schools can reduce the FCR risk of their parents, especially in the intermediate/high-risk categories. 


\section{Acknowledgments}

We are grateful to the Padre Anchieta University and City Hall of Campo Limpo Paulista - Sao Paulo, Brasil, whose support and encouragement made this research possible.

\section{Funding}

BC received a non-restricted grant (304352/2016/0) from Conselho Nacional de Desenvolvimento Científico e Tecnológico.

\section{Authors Contribuition}

Cristiano J. M. Pinto - Contributed substantially to the conception and the design of the study, collected and analysed the data, drafted and critically revised the manuscript.

Luciana S. Fornari - Elaborated the conception and the design of the study, supervised the study and participated in the analysis, interpretation of data and writing the manuscript.

Silvia M. R. Oyama; Maria M. D. Rodrigues; Taciana Davanço - Participated in collected and analysed the data, in designing one or more parts of the education program and/or the workplace intervention.

Bruno Caramelli - Elaborated the conception and the design of the study, supervised the study and participated in the analysis, interpretation of data and writing the manuscript.

\section{RESUMO}

OBJETIVO: Analisar se a implementação de um programa educacional multidisciplinar para prevenção cardiovascular em escolas públicas durante um ano pode contribuir para reduzir o escore de risco cardiovascular de Framingham dos pais das crianças.

MÉTODOs: Estudo prospectivo, de base comunitária, caso-controle em duas escolas públicas de São Paulo, Brasil. Os alunos foram randomizados para receber recomendações de estilo de vida saudável por duas abordagens diferentes. O grupo controle recebeu folhetos educacionais de saúde cardiovascular encaminhados para seus pais. O grupo intervenção recebeu os mesmos folhetos e as crianças foram expostas a um programa educacional semanal, durante um ano, com uma equipe multidisciplinar em prevenção cardiovascular. Dados clínicos e laboratoriais foram coletados no início e no final do estudo.

RESULTADOS: Foram sujeitos do estudo 418 pais das crianças das escolas. No início da pesquisa, o total de pais com escore de Framingham intermediário ou alto (risco superior a 10\% de doença cardiovascular nos próximos dez anos) foi de 6,9\% no grupo controle e de 13,3\% no grupo intervenção. Após um ano, dentre os pais com escore de risco de Framingham intermediário ou alto, foi observada redução de $22,2 \%$ no grupo intervenção e aumento de $33,3 \%$ no grupo controle ( $p=0,037)$. Os fatores de risco cardiovascular que melhoraram no grupo de intervenção foram pressão arterial, LDL-colesterol (lipoproteína de baixa densidade) e glicemia.

CONCLUSÃO: Um programa educacional de prevenção cardiovascular para crianças em idade escolar, em escolas públicas, pode reduzir o risco cardiovascular de seus pais.

PALAVRAS-CHAVE: Doenças cardiovasculares/prevenção e controle. Criança. Pais. Educação. Instituições acadêmicas.

\section{REFERENCES}

1. World Health Organization; World Heart Federation; World Stroke Organization. Global atlas on cardiovascular disease prevention and control. Geneva: World Health Organization; 2011. [cited 2020 Feb 27]. Available from: https://www.who.int/cardiovascular_diseases/publications/atlas_cvd/ en/

2. Brasil. Ministério da Saúde, Secretaria de Atenção à Saúde, Departamento de Atenção Básica. Prevenção clínica de doenças cardiovasculares, cerebrovasculares e renais. Brasília: Ministério da Saúde; 2006. [cited 2020 Feb 27] Available from: http://189.28.128.100/dab/docs/publicacoes/cadernos_ab/ abcad14.pdf

3. Bansilal S, Castellano JM, Fuster V. Global burden of CVD: focus on secondary prevention of cardiovascular disease. Int | Cardiol. 2015;201(Supp 1):S1-7.

4. Nobre MRC. Níveis de prevenção cardiovascular. Rev Soc Cardiol Estado de São Paulo. 2019;29(1):14-7.

5. Schwandt P, Haas GM. Family based prevention of cardiovascular disease risk factors in children by lifestyle change: the PEP Family Heart Study. Adv Exp Med Biol. 2019;1121:41-55.
6. Fornari LS, Giuliano I, Azevedo F, Pastana A, Vieira C, Caramelli B. Children First Study: how an educational program in cardiovascular prevention at school can improve parents' cardiovascular risk. Eur J Prev Cardiol. 2013;20(2):301-9.

7. Kipping RR, Jago R, Lawlor DA. Developing parent involvement in a schoolbased child obesity prevention intervention: a qualitative study and process evaluation. J Public Health (Oxf). 2012;34(2):236-44.

8. De Angelis K, Ferreira MJ, Ângelo LF. Intervenção não farmacológica em fatores de risco de forma individual. Rev Soc Cardiol Estado de São Paulo. 2019;29(2):137-45.

9. Malachias MVB, Souza WKSB, Plavnik FL, Rodrigues CIS, Brandão AA, Neves MFT, et al.; Sociedade Brasileira de Cardiologia. 7a Diretriz brasileira de hipertensão arterial. Arq Bras Cardiol. 2016;107(3 Supl 3):1-83.

10. Associação Brasileira de Empresas de Pesquisa. Critério de classificação econômica Brasil. 2012. [cited 2020 Feb 27]. Available from: http://www. abep.org/criterio-brasil

11. The Framingham Heart Study. A project of the National Heart, Lung and Blood Institute and Boston University. Cardiovascular 
disease (10-year risk). Risk score calculators. [cited 2020 Feb 27]. Available from: https://www.framinghamheartstudy.org/fhs-risk-functions/ cardiovascular-disease-10-year-risk/

12. Grundy SM, Cleeman JI, Merz CN, Brewer HB Jr, Clark LT, Hunninghake DB, et al; National Heart, Lung, and Blood Institute; American College of Cardiology Foundation; American Heart Association. Implications of recent clinical trials for the National Cholesterol Education Program Adult Treatment Panel III guidelines. Circulation. 2004;110(2):227-39.

13. Golan M, Weizman A, Fainaru M. Impact of treatment for childhood obesity on parental risk factors for cardiovascular disease. Prev Med. 1999;29(6 Pt 1):519-26.

14. Notara V, Antonogeorgos G, Kordoni ME, Sakellari E, Prapas C, Velentza A, et al. Family characteristics and children's knowledge of cardiovascular risk factors. Pediatr Int. 2018;60(12):1081-9.

15. Céspedes J, Briceño G, Farkouh ME, Vedanthan R, Baxter J, Leal M, et al. Targeting preschool children to promote cardiovascular health: cluster randomized trial. Am | Med. 2013;126(1):27-35.

16. Martins NS, Mello DSS, Barreto |, Soares AAS, Breder I, Cunha |, et al. Prevalence, treatment, and control of dyslipidemia in diabetic participants of two brazilian cohorts: a place far from heaven. Rev Assoc Med Bras. 2019;65(1):3-8.

17. Santos-Beneit G, Bodega P, de Miguel M, Rodríguez C, Carral V, Orrit X et al. Rationale and design of the SI! Program for health promotion in elementary students aged 6 to 11 years: a cluster randomized trial. Am Heart |. 2019;210:9-17. 